\title{
Oxalate-based high-capacity conversion anode for
}

\section{potassium storage}

Chang-Heum Jo, a Jae Hyeon Jo, a Ji Ung Choi, a Hitoshi Yashiro, ${ }^{b}$ Hyung Sub Kim ${ }^{a}$

and Seung-Taek Myung a, *

a Department of Nano Technology and Advanced Materials Engineering \& Sejong

Battery Institute, Sejong University, Gunja-dong, Gwangjin-gu, Seoul, 143-747,

Republic of Korea

${ }^{\mathrm{b}}$ Department of Chemistry and Bioengineering, Iwate University, Ueda 4-3-5,

Morioka, Iwate 020-8551, Japan

${ }^{c}$ Korea Atomic Energy Research Institute (KAERI) 70, Yuseong-daero 1312 beon-

gil, Yuseong-gu, Daejeon, Republic of Korea

Corresponding author: smyung@sejong.ac.kr

The number of pages: 9

The number of figures: 6 
The number of tables: 1 


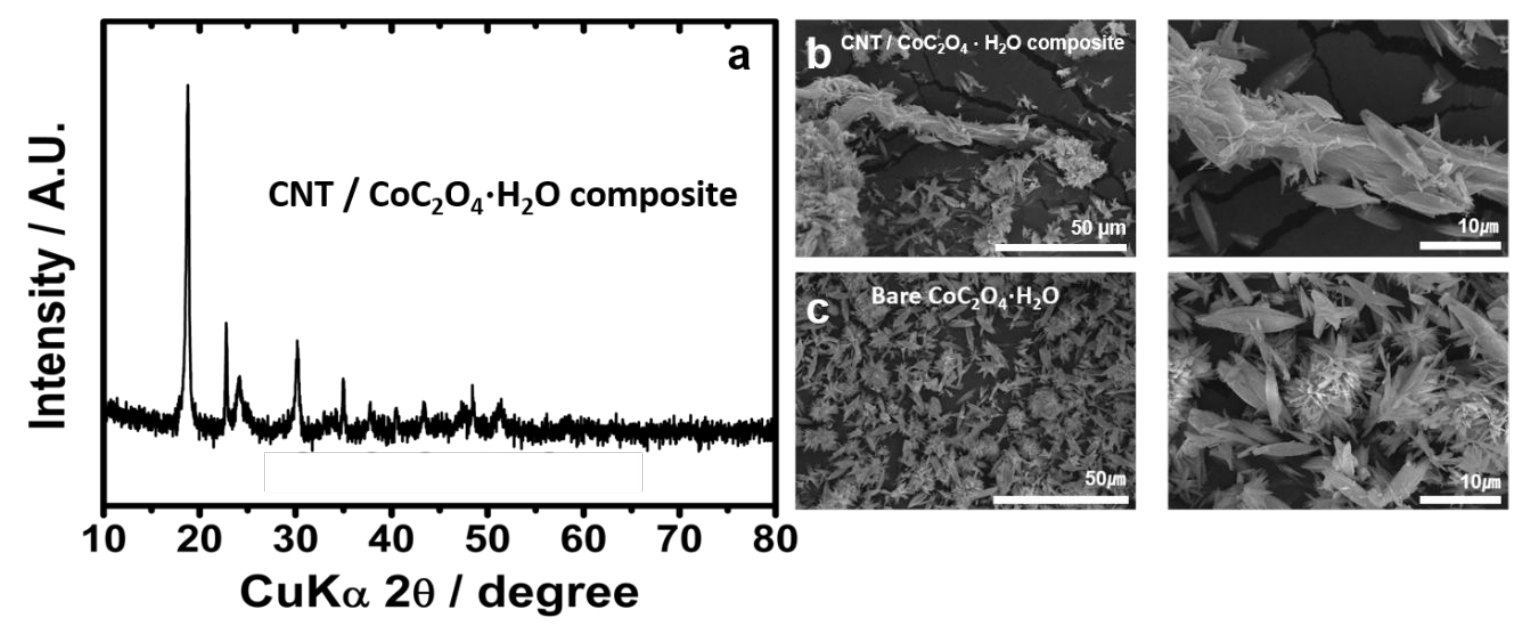

Figure S1. (a) XRD pattern and (b) SEM images of $\mathrm{CoC}_{2} \mathrm{O}_{4} \cdot \mathrm{H}_{2} \mathrm{O} / \mathrm{CNTS}$ composite with (left) low and (right) high magnification; (c) comparison with CNTs-free of $\mathrm{CoC}_{2} \mathrm{O}_{4} \cdot \mathrm{H}_{2} \mathrm{O}$. 
Table S1. Rietveld refinement results of the CNT embedded $\mathrm{CoC}_{2} \mathrm{O}_{4}$. (space group: $P 2_{1} / c$ )

\begin{tabular}{|c|c|c|c|c|c|c|}
\hline Atom & Site & $\mathbf{x}$ & $\mathbf{y}$ & $\mathbf{z}$ & g & $B / \AA^{2}$ \\
\hline Co & $2 \mathrm{a}$ & $\overline{0}$ & 0 & $\overline{0}$ & $0.999(1)$ & 0.9 \\
\hline 01 & $4 \mathrm{e}$ & $0.1901(3)$ & $0.0495(2)$ & $0.3189(2)$ & $2.025(2)$ & 1.1 \\
\hline O2 & $4 \mathrm{e}$ & $0.4701(5)$ & $0.6999(3)$ & $0.2491(3)$ & $1.971(2)$ & 1.1 \\
\hline C & $4 \mathrm{e}$ & $0.5489(1)$ & $0.8985(1)$ & $0.3989(2)$ & $2.002(1)$ & 1.3 \\
\hline \multirow{2}{*}{\multicolumn{2}{|c|}{ Cell parameter }} & \multicolumn{3}{|c|}{$\mathrm{a}=5.3289(1) \AA, \mathrm{b}=5.6045(2) \AA, \mathrm{c}=7.2327(3) \AA$} & \multicolumn{2}{|c|}{$\alpha=90^{\circ}, \beta=118.09(1)^{\circ}, \gamma=90^{\circ}$} \\
\hline & & \multicolumn{2}{|c|}{$R_{p}(\%): 10.2$} & $: 13.5$ & & \\
\hline
\end{tabular}




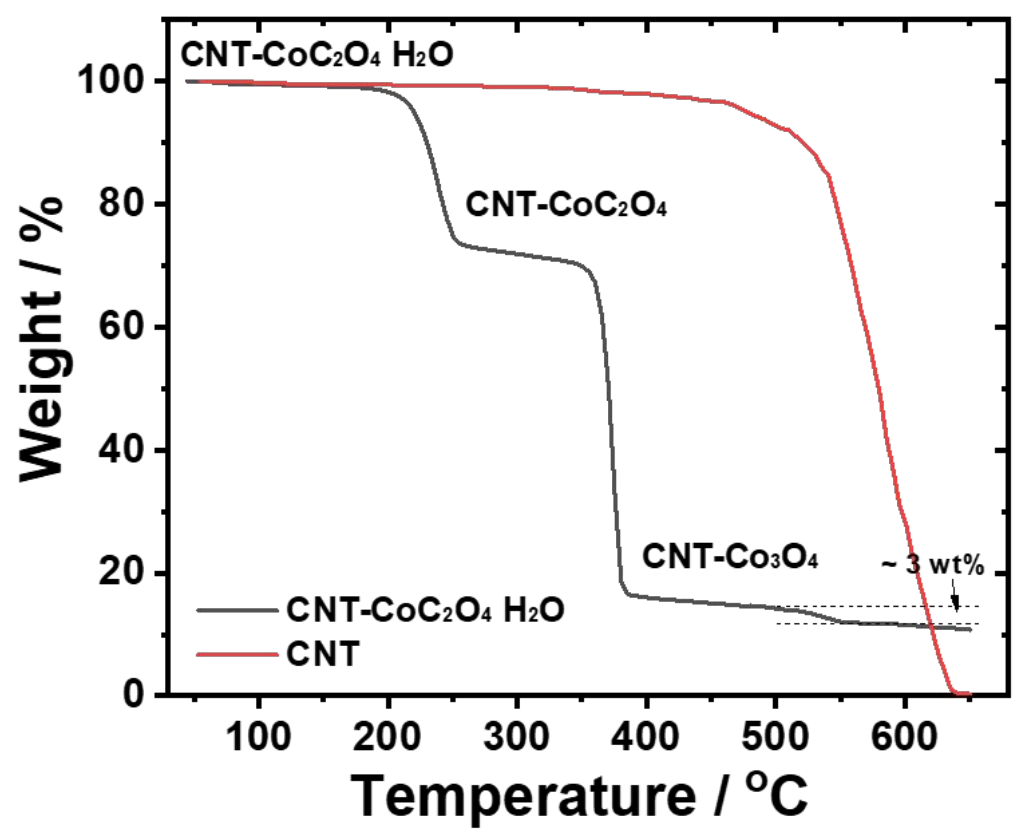

Figure S2. Comparison of TGA curves for CNTs and $\mathrm{CoC}_{2} \mathrm{O}_{4} \cdot \mathrm{H}_{2} \mathrm{O} / \mathrm{CNTs}$ composites. 


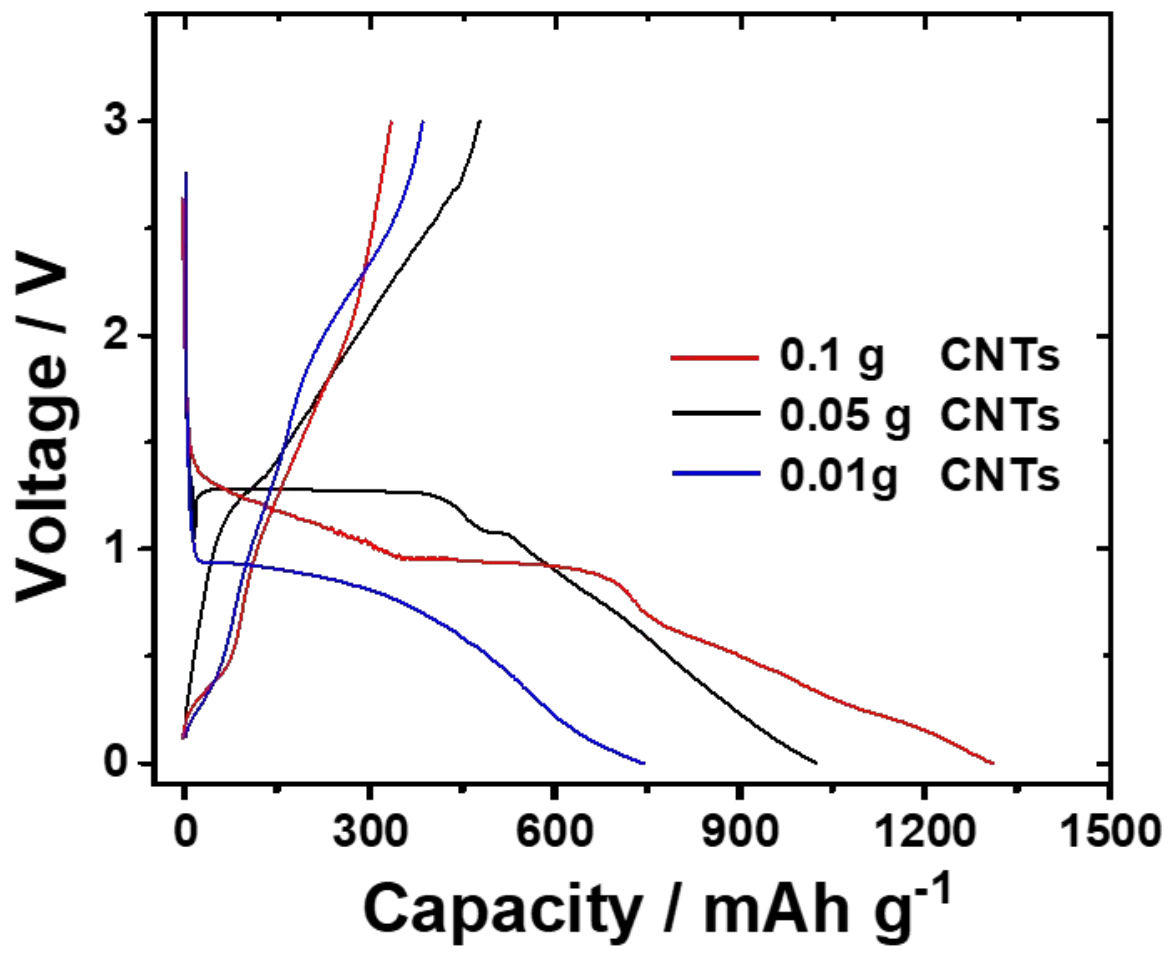

Figure S3. First charge and discharge curves of $\mathrm{CoC}_{2} \mathrm{O}_{4} / \mathrm{CNT}$ s composite electrodes tested at $40 \mathrm{~mA} \mathrm{~g}^{-1}$. Added CNTs were 1, 3, and 6 wt. \%. 


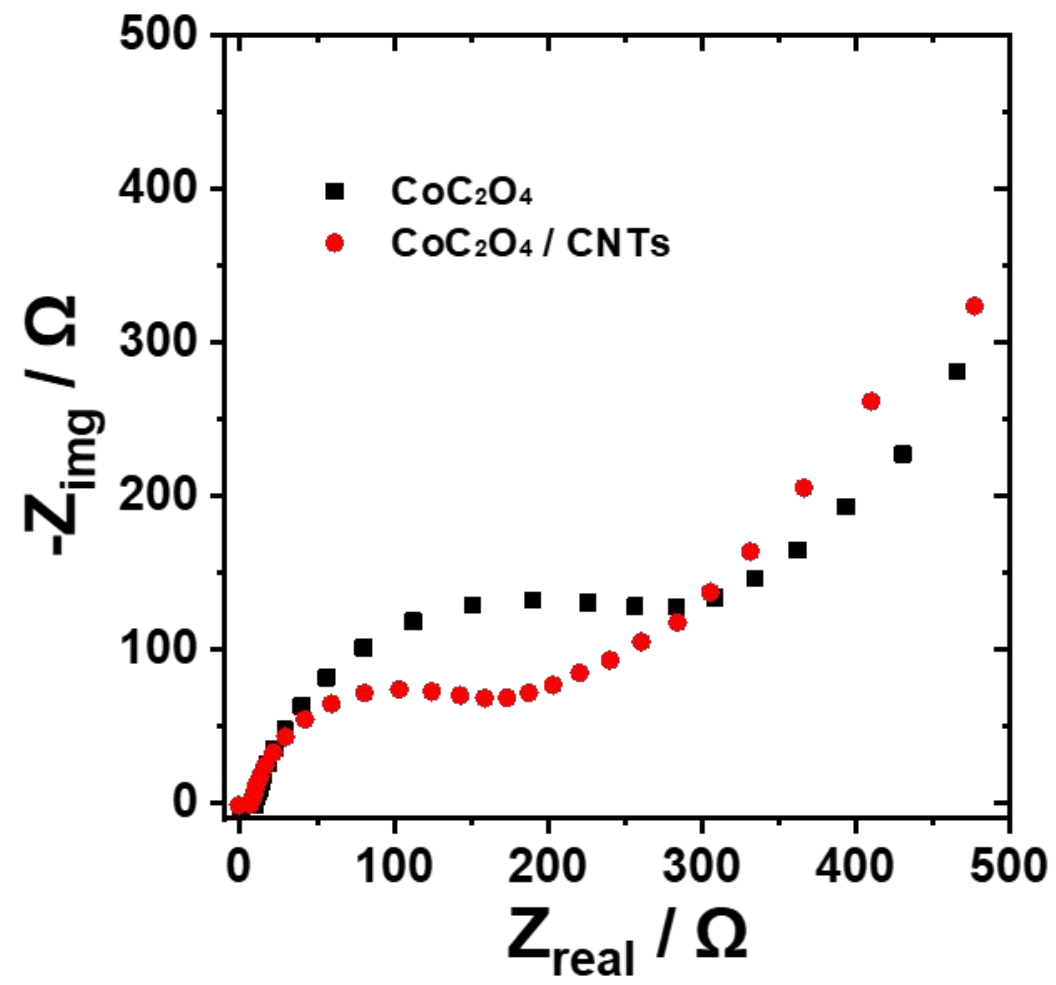

Figure S4. Cole-Cole plots of bare $\mathrm{CoC}_{2} \mathrm{O}_{4}$ and $\mathrm{CoC}_{2} \mathrm{O}_{4} / \mathrm{CNT}$ s composite electrodes in $\mathrm{K}$ cells. 


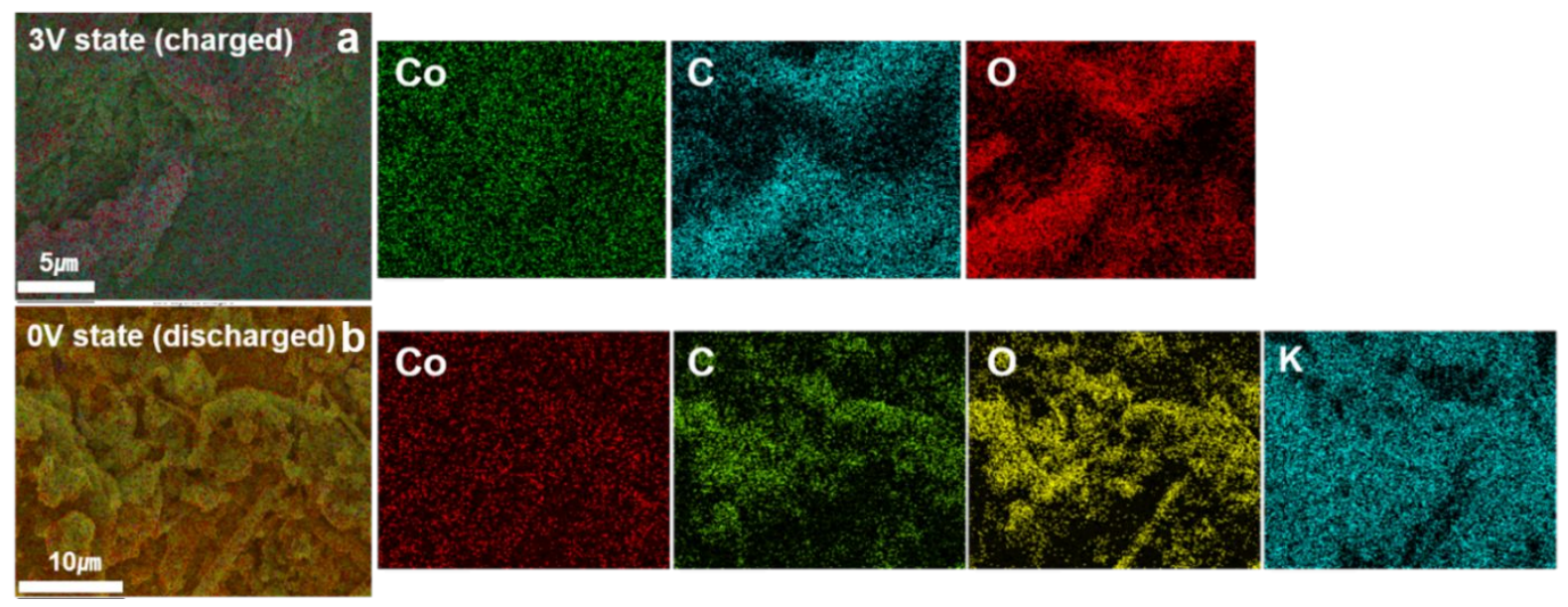

Figure S5. SEM mapping images for the $\mathrm{CoC}_{2} \mathrm{O}_{4} / \mathrm{CNTs}$ composite electrode (a) discharged to $0 \mathrm{~V}$ and (b) charged to $3 \mathrm{~V}$. 

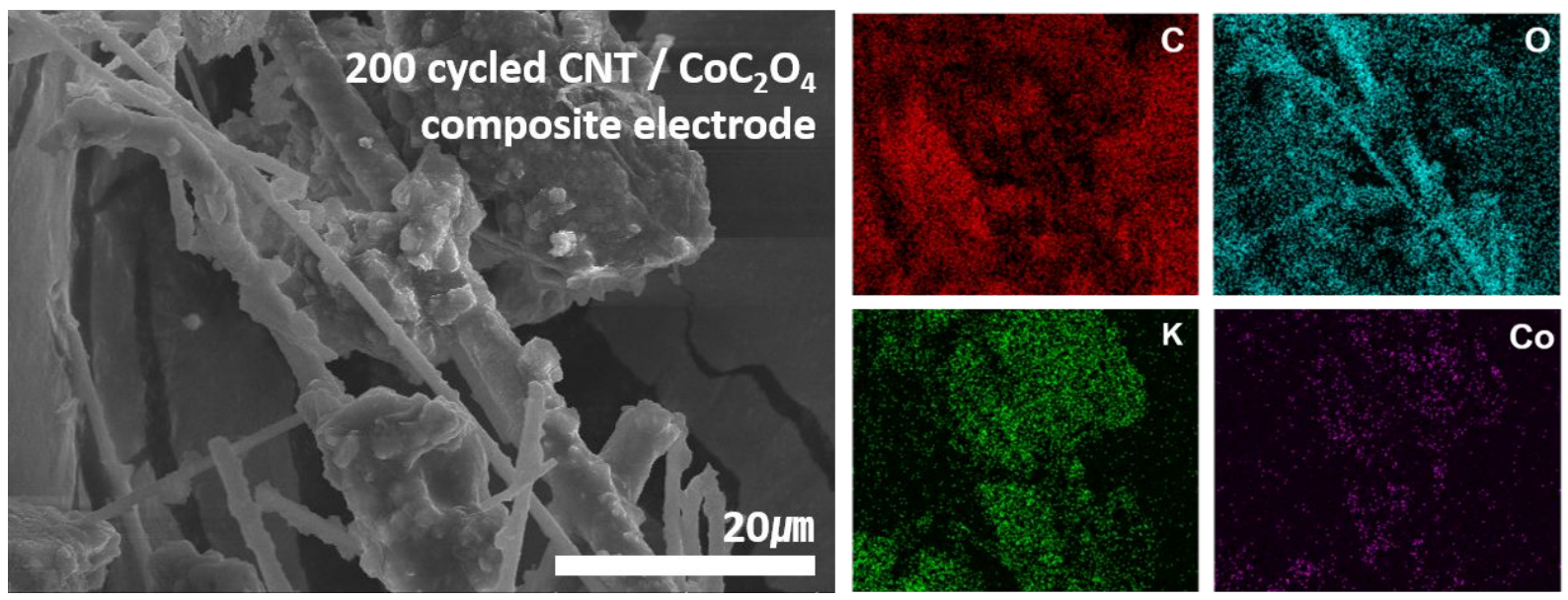

Figure S6. SEM image and the corresponding mapping images for the $\mathrm{CoC}_{2} \mathrm{O}_{4} / \mathrm{CNTs}$ composite electrode after 200 cycles. 